\title{
Distribution of Onryza maga (Leech, 1890) (Lepidoptera: Hesperiidae) with description of female genitalia and taxonomic notes
}

\author{
Guoxi Xue, Yufei Li, Zihao Liu, Meng Li \& Yingdang Ren
}

\begin{abstract}
Xue, G. X., Li, Y. F., Liu, Z. H., Li, M. \& Ren, Y. D. 2016: Distribution of Onryza maga (Leech, 1890) (Lepidoptera: Hesperiidae) with description of female genitalia and taxonomic notes. - Entomol. Fennica 27: 70-76.

For more than twenty years, Hainan, Vietnam, Myanmar, Thailand, Malaysia, Singapore and Indonesia have been erroneously reported in Chinese literature as belonging to the distribution range of Onryza maga (Leech 1890). Based upon a careful survey of specimens and relevant literature, these regions are omitted from the known range of this species. Onryza maga maga is found from northeast Guizhou, south Henan and Qinling-Daba Mountains in Shaanxi of China, its occurrence in Hunan is confirmed. The adults are redescribed and the variability of wing patterns is discussed. Female genitalia are illustrated and described for the first time. Some biological information and an updated distribution map of the species are provided.
\end{abstract}

G. X. Xue \& M. Li, School of Food and Bioengineering, Zhengzhou University of Light Industry, No. 5 Dongfeng Road, Zhengzhou, Henan, 450002, P. R. China; Corresponding author's e-mail: xueguoxi95227@163.com

Y. F. Li, School of Medicine, Xi'an Jiaotong University, No. 76 Yanta West Road, Xi'an, Shaanxi, 710061, P. R. China

Z. H. Liu, School of Physics, University of Science and Technology of China, No. 96 Jinzhai Road, Hefei, Anhui, 230026, P. R. China

Y. D. Ren, Institution of Plant Protection, Henan Academy of Agricultural Sciences, No.116 Huayuan Road, Zhengzhou, Henan, 450002, P. R. China

Received 4 November 2015, accepted 26 December 2015

\section{Introduction}

Onryza Watson, 1893 is a small genus including three species, namely $O$. maga (Leech), $O$. meiktila (de Nicéville) and O. siamica Riley \& Godfrey (Evans 1949, Devyatkin 1996). In some previous works, the distribution range of $O$. maga has been reported to cover the central and southern parts of China to Vietnam, Myanmar, Thailand, Malaysia, Singapore and Indonesia (Tong
1993, Chou 1994, Wu \& Li 1997, Chou 1998, Jiang et al. 2001, Wang \& Tang 2012). In the present paper, based upon a careful survey of literature and specimens, we conclude that the species appears to be restricted to the central and southern parts of the Chinese mainland and the island of Taiwan. It is reported for Guizhou, Henan and Shaanxi for the first time, and confirmed to occur in Hunan. Discovery of this species from Qinling-Daba Mountains in Shaanxi and Dabie 
Mountains in Henan extends the northern limit of the range to the boundary between the warm temperate zone and the subtropical zone of China.

Since the original description is deficient, morphological characters of O. maga maga (Leech) are redescribed in detail and the variability of wing pattern of both sexes is discussed, female genitalia are illustrated and described for the first time. Based upon an analysis of the specimens examined and investigations in the field, some biological information of this species is provided. An updated distribution map is given as well.

\section{Materials and methods}

Specimens listed below are deposited in the following collections in China:

- ZULI: Zhengzhou University of Light Industry, Zhengzhou, Henan

- SHNU: Shanghai Normal University, Shanghai

- YVTC: Yueyang Vocational Technical College, Yueyang, Hunan

- JNNR: Jiulianshan National Nature Reserve, Ganzhou, Jiangxi

- NAFU: Northwest A \& F University, Yangling, Shaanxi

- CHWB: Chunhao Wang, Beijing

- YFLX: Yufei Li, Xi'an, Shaanxi

- ZHLH: Zihao Liu, Hefei, Anhui

- LPZB: Liping Zhou, Baoji, Shaanxi.

Geographic coordinates of the collecting sites are based upon http://www.gpsspg.com/maps.htm.

The following specimens of Onryza maga maga (Leech) from China were examined: Shaanxi province: 10, Erliguan village

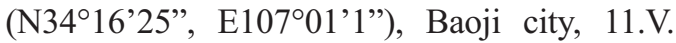
2010, Chunhao Wang leg. (CHWB); 2 우,

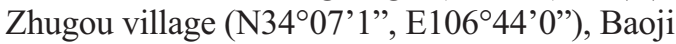
city, V.2010, Liping Zhou leg. (LPZB, photos examined); $8 \hat{\widehat{\partial}} \hat{0}, 3$ 우우, Xunyangba township (N33 $33^{\prime} 6^{\prime \prime}$, E108 $\left.32^{\prime} 40^{\prime \prime}\right)$, Ningshan county, 15.VI.1997, 10--11.VI.2000, 18.-19.V.2011,

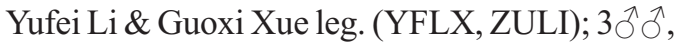
Zhanghe township (N32 $05^{\prime} 13^{\prime \prime}$, E108'53'59”), Langao county, 29.VII.2012, 21.VII.2013,
Guoxi Xue, Xinglong Jia, Wenhao Nan \& Yufei Li leg. (ZULI); 10, Zhenping county, 10.VIII.2002, Yufei Li \& Jianxin Shou leg. (ZULI); 10, Shangzhu township (N31 ${ }^{\circ} 54^{\prime} 54^{\prime \prime}$, E109²5'56"), Zhenping county, 25.VII.2014, Guoxi Xue \& Meng Li leg. (ZULI). Henan province: $1 \widehat{0}, 1+$, Liankangshan National Nature Reserve (N31'37'26”, E11448'32'), Xin county, 27.IV.2014, Guoxi Xue \& Meng Li leg. (ZULI). Anhui province: $2 \hat{\widehat{\partial}} \hat{)}, 1$ 우, Fuxi village (N3004'46”, E118 $\left.08^{\prime} 50^{\prime \prime}\right)$, Huangshan city, 4.VII.2011, Zihao Liu leg. (ZHLH). Hunan pro-

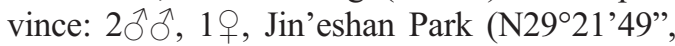
E11306'43"), Yueyang city, 11.VIII.2009, 26.IV.2011, 15.VI.2011, Xinggang Wu leg. (YVTC). Guizhou Province: $1 \delta^{\widehat{ }}$, Fanjing Mountain (N27 54'40", E108³8'32”), Jiangkou county, 10.VI.2015, Guoxi Xue leg. (ZULI). Guangxi Zhuang Autonomous Region: $25 \hat{\delta} \widehat{\partial}$,

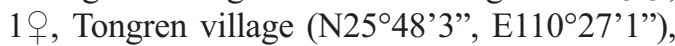
Huajiang township, Xing'an county, 26.28.V.2015, Guoxi Xue leg. (ZULI). Zhejiang province: $4 \hat{\jmath} \hat{0}, 1$, , West Tianmu mountain (N30¹8'52”, E119²6'34"), 1.VIII.2007, 27.IV. 2008, 11.IV.2009, Hao Huang leg. (SHNU, photos examined). Fujian province: $3 \hat{\jmath} \widehat{\partial}, 2$ 우의, Longqishan National Nature Reserve

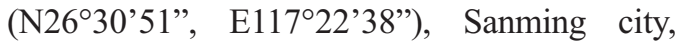
5.VIII.2006, Xiangqun Yuan leg. (NAFU). Jiangxi province: $60^{\lambda} \hat{0}$, Suichuan county (exact location unknown), 28.VII.-12.VIII.2004, Xiangqun Yuan \& Yanxia Chen leg. (NAFU);

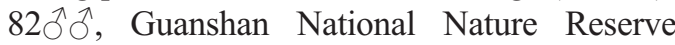
(N2833'19”, E11435'0'), Yifeng county, 11.14.VIII.2012, Guoxi Xue, Xinglong Jia \& Wenhao Nan leg. (ZULI); $17 \widehat{\partial}^{\lambda}$, Jiulianshan National Nature Reserve (N24'34'46", E114 $\left.26^{\prime} 8^{\prime \prime}\right)$, Longnan county, 20.III.-1.IV., 20.V., 17.VIII.2012, Hualin Hu, Guoxi Xue, Xinglong Jia \& Wenhao Nan leg. (ZULI, JNNR).

Terminology for venation system and female genitalia follows Evans (1949) and Klots (1970), respectively.

\section{Onryza maga (Leech, 1890) (Figs. 1, 2)}

Pamphila maga Leech, 1890: 48 (original description). 

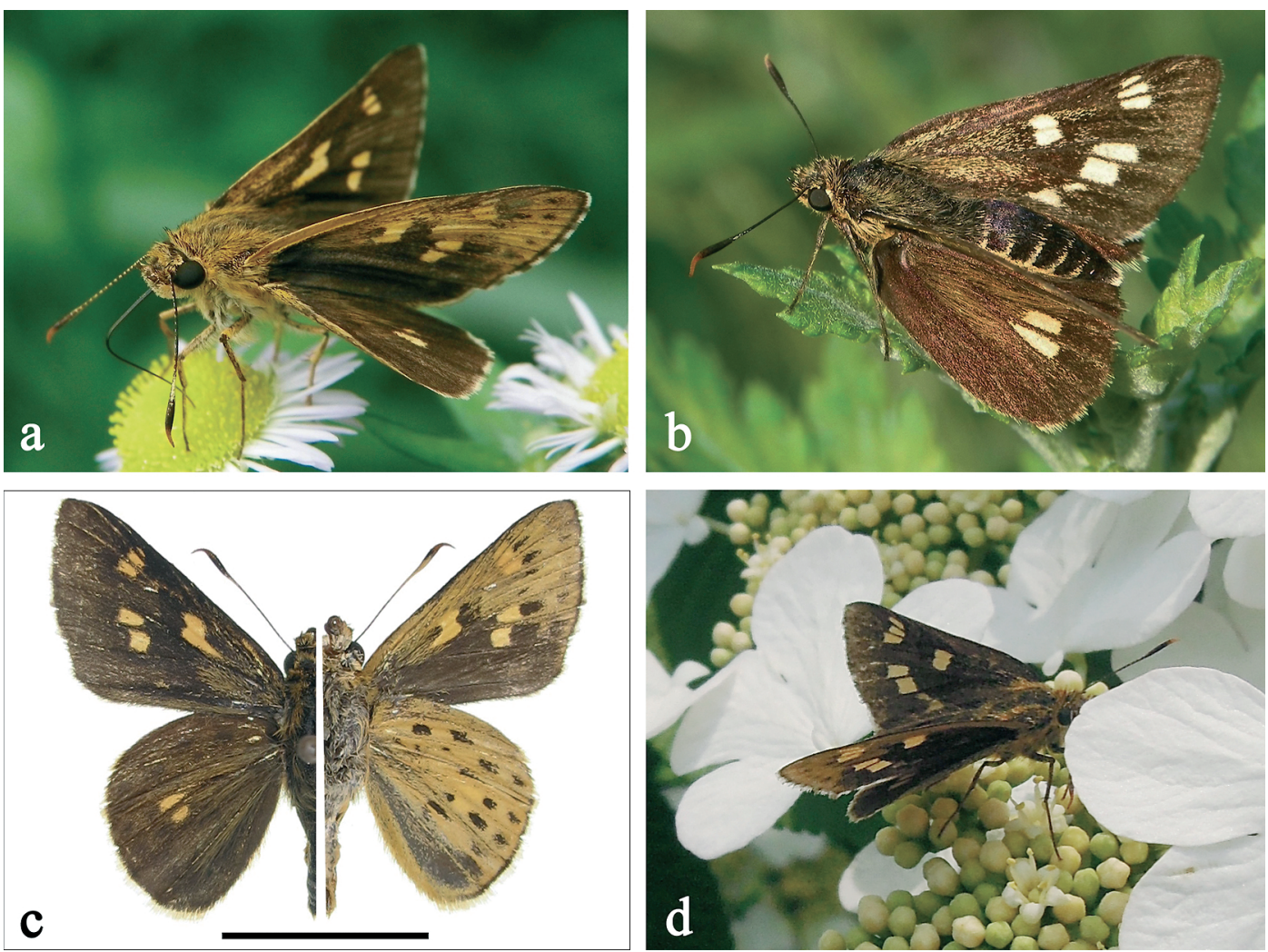

Fig. 1. Adults of Onryza maga (Leech, 1890). - a. Male, Jin'eshan Park, Yueyang city, Hunan province, 15.VI.2011, photo by Xingang Wu. - b. Female, same locality as the previous male, 26.IV.2011, photo by Xingang Wu. - c. Male, Shangzhu township, Zhenping county, Shaanxi province, 25.VII.2014, photo by Guoxi Xue, scale bar $10 \mathrm{~mm}$. - d. Female, Liankangshan National Nature Reserve, Xin county, Henan province, 27.IV.2014, photo by Meng Li.

Padraona maga: Leech (1894: 599) (description, distribution).

Ampittia maga: Elwes \& Edwards (1897: 186) (key); Seitz (1906: 345) (brief description); Wong \& Tao (1934: 76) (list).

Onryza maga: Evans (1949: 251) (key, distribution); Bridges (1994: 132) (catalogue); Chou (1994: 722) (brief description, distribution); Chou (1998: 290) (key).

\subsection{Redescription}

Male (Fig. 1a, c). Antennae: 7-8 $\mathrm{mm}$ in length, dorsal side dark-brown, ventral side of shaft with yellow rings, club covered with yellow scales, apiculus dull red and sharply pointed. Labial palpi: covered with whitish-yellow scales and hairs, third segment black and porrect. Thorax and ab- domen: dorsal side covered with brown hairs, ventral side and legs with yellow scales. Forewing: $15-16 \mathrm{~mm}$ in length, dorsal side darkbrown with yellow markings, proximally covered with brownish-green scales; apical spots in spaces 6-8 arranged in an oblique line, the one in space 8 slightly moved outwards; upper and lower cell spot connected, lower one needleshaped and extended to middle of cell; a cuniform spot at base of space 3, partly overlapped by the quadrate spot in space 2; a tiny dot adjacent to vein 1 in middle of space $1 \mathrm{~b}$ sometimes visible. On ventral side, costal area, apical area and upper discal area suffused with yellow scales, lower discal area and dorsum area dark-brown; yellow spots as on dorsal side, the apical ones distally with dark strips; a series of dark marginal spots from apex to space $1 \mathrm{~b}$ prominent or obscure. Hindwing: dorsal side dark brown, central area 


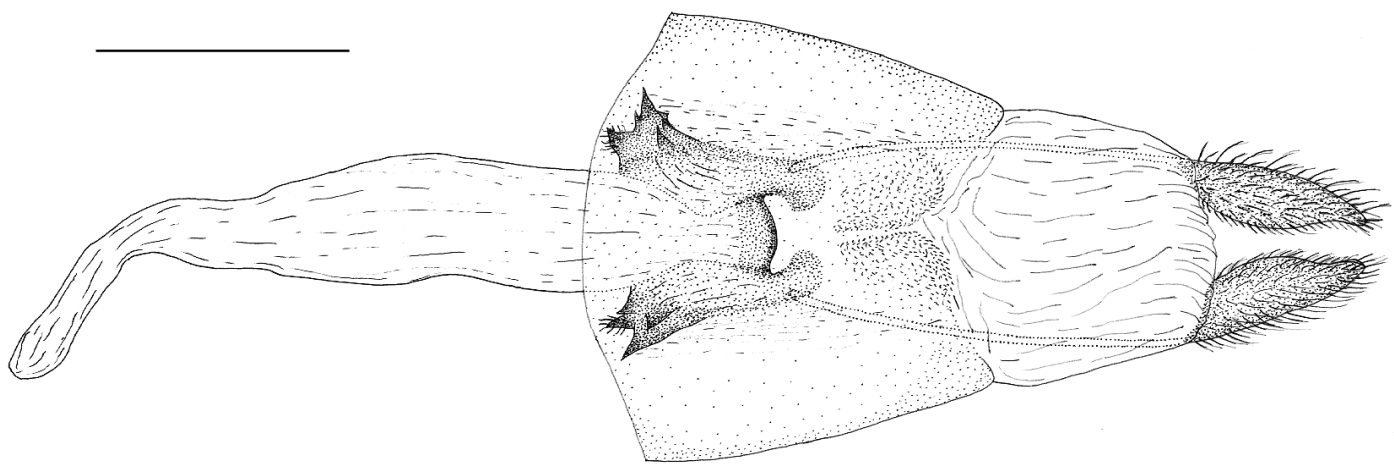

Fig. 2. Female genitalia of Onryza maga (Leech, 1890). Xunyangba township, Ningshan county, Shaanxi province, 19.V.2011. Scale bar $1 \mathrm{~mm}$.

broadly covered with brownish-green scales and hairs; space 3 with a yellow spot, below which a spot in space 2 sometimes vestigial. Ventral side clad with yellow scales, space $1 \mathrm{~b}$ blackish; in each space from 7 to $1 \mathrm{c}$ there are two or three small black spots forming the discal and marginal series, but in some individuals these spots maybe faded. Cilia on both wings white or yellowish, sometimes checkered with black at end of veins.

Female (Fig. 1b, d). The lower cell spot on forewing merged with the upper one, not extended towards wing base; two separated spots sometimes present in middle of space $1 \mathrm{~b}$.

Female genitalia (Fig. 2). Papillae anales triangular in shape, covered with long hairs. Apophyses posteriores 2.5 times as long as papillae anales. Lamella postvaginalis membranous, middle part slightly sclerotic and with tiny hairs. Middle of lamella antevaginalis transparent, with four or five strongly sclerotized sharp horns on each side, of which the front one with tiny hairs. Ductus bursae and bursa copulatrix bursiform, membranous, without signum.

Variability. On the forewing, apical spots in spaces 6-8 may be long or very short, with the one in space 6 sometimes invisible; spots in spaces 3 and 2 always exist, but in one male specimen from Shaanxi, the size of these two spots are much smaller than usual; length ratio between the lower cell spot and the upper one in male changes from 1.5 to 4; one female from Shaanxi exhibits two very narrow cell spots which tend to be disappeared; two male specimens from Zhejiang have a vestigial slanted spot in space $1 \mathrm{~b}$. On the dorsal side of hindwing, the spot in space 3 is always well developed, but the one in space 2 is usually smaller or even absent; on the ventral side, two big black spots generally exist in space 7 , but in some individuals they are small or completely missing. Among the females we have examined, the one from Hunan seems much paler (Fig. 1b), while the others are all normal in color.

Remarks. Externally, Onryza maga and Ampittia virgata (Leech) are similar, and their distribution ranges largely overlap, but they can be separated by the following combination of characters on the dorsal side of forewing: A. virgata has a yellow costal streak, vein 5 originates in the middle of vein 4 and vein 6 , male has a black stigma in space $1 \mathrm{~b}$; whereas in $O$. maga there are no costal streak and stigma and the base of vein 5 is closer to vein 4 than to vein 6 .

\subsection{Bionomics}

The species has three generations, mainly emerging in April, June and mid-July to August across most of its distribution range. In south Shaanxi, the first generation appears in May, possibly because of the higher latitude and the slower rise in temperature after winter in this area.

Among the specimens we have examined, females are clearly less numerous than males, a remarkable example is that we collected 82 males but no female in August of 2012 in Guanshan National Natural Reserve of Jiangxi. There we observed also an interesting phenomenon: some individuals were laying on the ground like drunkards, with their ventral side upturned. When dis- 


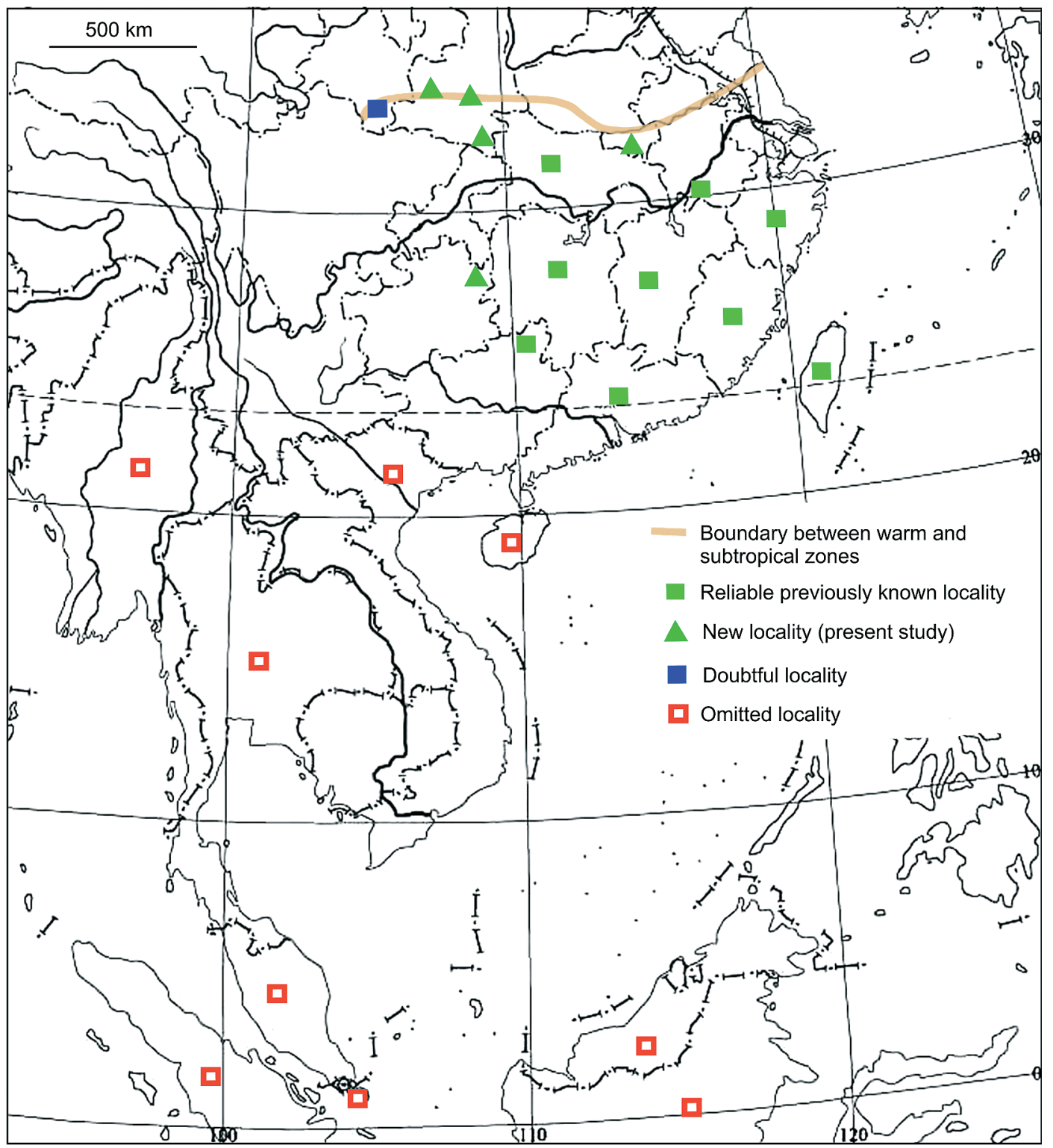

Fig. 3. Distribution map of Onryza maga (Leech, 1890).

turbed, they flapped their wings and turned over, then flew to the plants nearby. The reason for this behavior is unclear, but we saw the skippers sucking cement paste on the ground that leaked out of the trucks from a road construction site in the natural reserve. We guess that chemical substances in the cement paste made the skippers "drunk".

In Liankangshan National Natural Reserve of Henan, we found this species visiting flowers of Viburnum plicatum Thunb. f. tomentosum (Thunb.) Miq. (Caprifoliaceae) (Fig. 1d).

\subsection{Distribution}

China: SE Gansu (?), S Shaanxi, Hubei, S Henan, S Anhui, Zhejiang, Fujian, Jiangxi, Hunan, Guangdong, Guangxi, NE Guizhou, Taiwan.

Remarks. Two subspecies of Onryza maga are known, viz. O. maga maga and O. maga takeuchii (Matsumura). The latter is endemic to Taiwan, without the black spots on the dorsal side of wings (Shirôzu 1960, Hsu et al. 2006). Tong (1993), Chou (1994), Wu \& Li (1997), Chou 
(1998) Jiang et al. (2001) and Wang \& Tang (2012) listed Hainan, Vietnam, Myanmar, Thailand, Malaysia, Singapore and Indonesia in the distribution of $O$. maga, but these records must be based upon misidentified specimens or erroneous information. Indeed, in the works dealing with butterfly fauna of the above-mentioned areas $O$. maga has never been reported (Inoué \& Kawazoé 1964, 1965, 1966, 1967, 1970, Eliot 1992, Devyatkin 1996, Gu \& Chen 1997, Devyatkin \& Monastyrski, 1999, Osada et al. 1999, Devyatkin 2000, 2002, Gu 2002, Devyatkin 2003, Hsu et al. 2006, Ek-Amnuay 2006, Chiba 2008). We therefore omit these localities from the distribution range of the species. Chen et al. (2006) included O. maga in a list of butterflies from southwest Hunan without providing any further information. Five years later Xin-Gang Wu photographed this species from Yueyang in north Hunan (Fig. $1 \mathrm{a}, \mathrm{b})$ in June of 2011, and thus confirmed its existence in this province which fills the gap between Guangxi, Hubei and Jiangxi. Cai et al. (2011) reported this species from southeast Gansu, but we hesitate to trust this record since there were no images, collecting data or diagnostic features provided. As a result of the present study, O. maga was discovered in Qinling-Daba Mountains and Dabie Mountains. Accordingly, the northern limit of its distribution range is extended to the northern border of the subtropical zone of China. Fanjing Mountain in northeast Guizhou is also a new locality for this species. An updated distribution map of O. maga is given in Fig. 3, based upon the specimens examined and data from reliable references (Leech 1890, 1892-1894, Seitz 1906, Evans 1949, Shirôzu 1960).

Acknowledgements. We express our sincere thanks to the following friends: Mr Xingang Wu (Hunan), Mr Hualin $\mathrm{Hu}$ (Jiangxi), Mr Chunhao Wang (Beijing), Mr Liping Zhou (Shaanxi), Dr Hideyuki Chiba (Fukuoka), Dr Yufeng Hsu (Taiwan), Mr Vadim V. Tshikolovets (Kiev), Mr Jianqing Zhu (Shanghai) and the colleagues in Maoershan National Nature Reserve and Fanjingshan National Nature Reserve. Two anonymous reviewers provided constructive suggestions to an earlier version of this paper. The first author would express special thanks to Prof. Junsong Zhang (Henan) and Mr Hai Yang (Henan) for their kind help. Field surveys in Henan Province were funded by the Administrative Bureau of Liankangshan National Nature Reserve. This study is supported by the National Natural Science Foundation of China (No. 41401067, No. 31172141).

\section{References}

Bridges, C. A. 1994: Catalogue of the family-group, genus-group and species-group names of the Hesperioidea (Lepidoptera) of the world. - Charles A. Bridges, Illinois. I. ii-XIII. 9 pp.

Cai, J. Z., Yang, Q. S., Li, Q., Guo, H. \& Zhang, Y. 2011: Butterfly resources in Gansu Xiaolongshan forest area (V). - Gansu Agricultural Science and Technology 5: 23-26.

Chen, Y. J., Li, Y. Y., Dou, T. S. \& Wang, C. C. 2006: Investigation on butterflies resource in Shunhuangshan Mountain National Forest Park of Dong'an County in Hunan. - Journal of Hunan Agricultural University (Natural Sciences) 32(4): 398-401.

Chiba, H. 2008: Skippers of Hainan (Lepidoptera: Hesperiidae). - Report on Insect Inventory Project in Tropical Asia (TAIIV) 337-344.

Chou, I. (ed.) 1994: Monographia Rhopalocerorum Sinensium 1 \& 2. (Revised Edition). - Henan Scientific and Technological Publishing House, Zhengzhou. 852 pp.

Chou, I. 1998: Classification and identification of Chinese butterflies. - Henan Scientific and Technological Publishing House, Zhengzhou. 349 pp.

Devyatkin, A. L. 1996: New Hesperiidae from North Vietnam, with the description of a new genus (Lepidoptera, Rhopalocera). - Atalanta 27(3/4): 595-604.

Devyatkin, A. L. 2000: Hesperiidae of Vietnam, 7. A contribution to the Hesperiidae fauna of the southern Vietnam (Lepidoptera). - Atalanta 31(1/2): 198-204.

Devyatkin, A. L. 2002: Hesperiidae of Vietnam, 12. A further contribution to the Hesperiidae fauna of North and Central Vietnam. - Atalanta 33(1/2): 137-155.

Devyatkin, A. L. 2003: Hesperiidae of Vietnam, 15. New records of Hesperiidae from southern Vietnam (Lepidoptera: Hesperiidae). — Atalanta 34(1/2): 119-133.

Devyatkin, A. L. \& Monastyrskii, A. L. 1999: Hesperiidae of Vietnam, 5. An annotated list of the Hesperiidae of North and Central Vietnam (Lepidoptera, Hesperiidae). - Atalanta 29(1/4): 151-184.

Ek-Amnuay, P. 2006: Butterflies of Thailand. Fascinating insects Vol. 2 ( $1^{\text {st }}$ edition). - Amarin Printing and Publishing, Bangkok. 849 pp.

Eliot, J. N. 1992: The butterflies of the Malay Peninsula ( $4^{\text {th }}$ revised edition) (originally by Corbet, A. S. \& Pendlebury, H. M.). - Malayan Nature Society, Kuala Lumpur. 595 pp.

Elwes, H. J. \& Edwards, J. 1897: A revision of the Oriental Hesperiidae. - Transactions of the Zoological Society of London 14(4): 101-324, pls. 18-27.

Evans, B. W. H. 1949: A catalogue of Hesperiidae from Europe, Asia and Australia in the British Museum (Natural History). - The British Museum, London. $\mathrm{v}-\mathrm{xiv}+502 \mathrm{pp}$.

Gu, M. B. \& Chen, P. Z. 1997: Butterflies in Hainan Island. - China Forestry Publishing House, Beijing. 355 pp.

Gu, M. B. 2002: Lepidoptera: Rhopalocera. — In: Huang F. S. (ed.), Forest insects of Hainan: 654-716. Science Press, Beijing. 1064 pp. 
Hsu, Y. F., Chiba, H., Yang, Y. C., Tsukiyama, H., Yang, P. P. \& Wang, S. M. 2006: A taxonomic review of the Taiwanese skippers described by Shonen Matsumura (Lepidoptera: Hesperiidae). — Zoological Studies 45(3): 322-338.

Inoué, S. \& Kawazoé, A. 1964: Hesperiid butterflies from South Vietnam (1). — Tyô to Ga 15(2): 34-50.

Inoué, S. \& Kawazoé, A. 1965: Hesperiid butterflies from South Vietnam (2). — Tyô to Ga 15(4): 84-105.

Inoué, S. \& Kawazoé, A. 1966: Hesperiid butterflies from South Vietnam (3). - Tyô to Ga 16(3/4): 84-103.

Inoué, S. \& Kawazoé, A. 1967: Hesperiid butterflies from South Vietnam (4). — Tyô to Ga 17(1 \& 2): 1-17.

Inoué, S. \& Kawazoé, A. 1970: Hesperiid butterflies from South Vietnam (5). - Tyô to Ga 21(1 \& 2): 1-14.

Jiang, F., Qi, S. C., Huang, B. K. \& Yao, L. H. 2001: Lepidoptera: Rhopalocera. - In: Huang, B. K. (ed.), Fauna of insects in Fujian Province of China, Vol. 4: 1165. Fujian Science and Technology Publishing House, Fuzhou. 165 pp.

Klots, A. B. 1970: Lepidoptera. — In: Tuxen, S. L. (ed.), Taxonomist's Glossary of Genitalia in Insects $\left(2^{\text {nd }}\right.$ edition): 115-130. Copenhagen, Munksgaard, 213 pp.

Leech, J. H. 1890: New species of Lepidoptera from China. - The Entomologist 23(320): 26-50.
Leech, J. H. 1892-1894: Butterflies from China, Japan and Corea. - John Henry Leech, London. 681 pp.

Osada, S., Umura, Y. \& Uehara, J. 1999: An illustrated checklist of the butterflies of Laos P. D. R. - Mokuyo-sha, Tokyo. 240 pp.

Seitz, A. 1906: The Macrolepidoptera of the world. Section 1. The Macrolepidoptera of the Palaearctic Region. Vol. 1. The Palaearctic butterflies. - Alfred Kernen Publisher, Stuttgart. 379 pp.

Shirôzu, T. 1960: Butterflies of Formosa in color. - Hoikusha Publishing Co., Ltd, Osaka. 481 pp.

Tong, X. S. (ed.) 1993: Butterfly fauna of Zhejiang. Zhejiang Science and Technology Press, Hangzhou. $87 \mathrm{pp}$.

Wang, M. \& Tang, D. M. 2012: Butterflies of Guangxi Maoershan National Nature Reserve. - Guangxi Nationalities Publishing House, Nanning. 66 pp., 113 pls.

Wong, C. Y. \& Tao, C. C. 1934: A list of the butterflies of Chekiang in the Bureau. - 1933 Year Book of Bureau of Entomology 3: 33-76.

Wu, C. X. \& Li, X. J. 1997: Butterflies and moths of Mount Huang. - Anhui Science and Technology Press, Hefei. $218 \mathrm{pp}$. 